\title{
Accessing HIV-1 Protease Inhibitors through Visible-Light-Mediated Sequential Photocatalytic Decarboxylative Radical Conjugate Addi- tion-Elimination-Oxa-Michael Reactions
}

\author{
Tomislav Krolo, Aditya Bhattacharyya, Oliver Reiser* \\ Institut für Organische Chemie, Universität Regensburg, Universitätsstraße 31, 93053 Regensburg, Germany
}

\begin{abstract}
A novel photocatalytic decarboxylative radical conjugate addition-elimination-oxa-Michael reaction of hydroxyalkylated carboxylic acids with cyclopentenones has been developed to construct diverse cyclopentanonyl-fused functionalized cyclic ether derivatives in the presence of an inexpensive organic photocatalyst. The stereoselective synthetic strategy is amenable to substructural variation, establishing a direct total synthetic route to two diastereomers of C3-Amino cyclopentyltetrahydrofuranyl-derived potent HIV-1 protease inhibitors with low nanomolar $\mathrm{IC}_{50}$ values.
\end{abstract}

\section{INTRODUCTION}

Cyclopentanonyl-fused small-sized, 5-7-membered cyclic ethers are a privileged class of heterocyclic motifs frequently found in many natural-occurring organic compounds and drug candidates with intriguing biological properties (Figure 1). For instance, the cyclopentanonyl-fused tetrahydrofuran (CpO-THF) framework occurs in a functionalized ergosteroid, asperflotone (I), which demonstrates inhibitory activity against lipopolysaccharide-activated IL-6 production in THP-1 cells $\left(\mathrm{IC}_{50}=22 \mu \mathrm{M}\right)^{1}$ and in A-seco limonoid zumsin (II) that shows potent antifeedant activities. ${ }^{2}$ In addition, the CpO-THF motif is found in synthetic intermediates in total syntheses of various natural products such as $(-)$ platensimycin, ${ }^{3}$ resiniferatoxin, ${ }^{4}$ oolongtheanins, ${ }^{5}$ and Thromboxane $\mathrm{A}_{2}{ }^{6}$ Its carbonyl-reduced form, i.e. the cyclopentyl-fused tetrahydrofuran (Cp-THF) moiety is also a pharmacologically significant molecular framework which occurs in several natural prostaglandins such as $\mathrm{PGI}_{2}$ and Beraprost. ${ }^{7}$ Most notably, a series of extremely potent HIV-1 protease inhibitors III-V containing the Cp-THF core was designed and synthesized by Ghosh and co-workers ${ }^{8}$ addressing the complications related to the emergence of drug resistance in antiretroviral therapies and drawing inspiration from the success of Darunavir, an FDAapproved drug for HIV/AIDS patients $\left(\mathrm{IC}_{50}=3 \mathrm{nM}\right)$. Subsequent structural analysis revealed that appropriate functionalization at the C3-position of the Cp-THF moiety could effectively enhance the potency of the drug candidates. The diastereomeric GRL-0249A $\left(\mathrm{IV}, \mathrm{IC}_{50}=1.6 \mathrm{nM} ; \mathrm{K}_{\mathrm{i}}=1.8 \mathrm{pm}\right)$ and GRL-0289A $\left(\mathrm{V}, \mathrm{IC}_{50}=4.6 \mathrm{nM}\right.$; $\mathrm{K}_{\mathrm{i}}=4.0 \mathrm{pm}$ ) bearing a $\mathrm{N}$-methyl carbamate group at the C3-position were found to be among the most effective candidates compared to the C3-unsubstituted (III, GRL-06579A, $\mathrm{IC}_{50}=1.8 \mathrm{nM}$ ) or hydroxy-substituted $\left(\mathrm{IC}_{50}=2.9 \mathrm{nM}\right)$ derivatives. ${ }^{8}$ The one- and two carbon higher homologues of the CpO-THF motif also construct molecular cores of biologically active natural products such as the phloroglucinol derivative Myrtucommulone J (VI), ${ }^{9}$ prostaglandin by-product VII, ${ }^{10}$ and heartwood root and leaf-constituent hypertricone (VIII). ${ }^{11}$

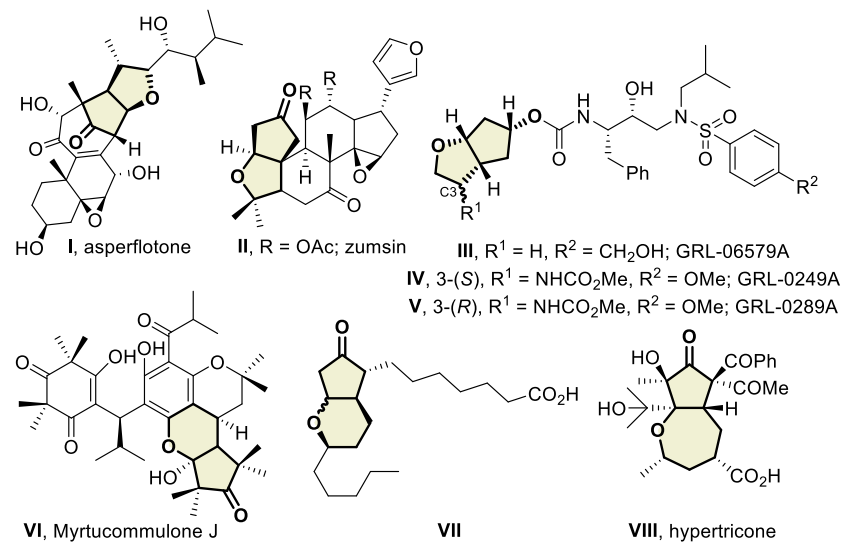

Figure 1. A few representative examples of cyclopentanyl- and cyclopentanonyl-fused cyclic ethers in natural products and drug candidates.

Several methods for the construction of CpO-THF scaffolds have been developed including conjugate addition of mixed vinyl cuprates to THF-fused cyclopentenals followed by trapping with TMSCl and subsequent ozonolysis, ${ }^{12}$ Swern oxidation of the corresponding alcoholic precursors, ${ }^{13}$ intramolecular oxa-Michael addition to enones, ${ }^{4,14}$ intramolecular cyclization of hydroxyimines, ${ }^{15} 5$ exo-cyclization of alkyl radicals to ketene intermediates, ${ }^{16}$ and $\mathrm{Ni}$ catalyzed cyclization of alkynylenones in the presence of organozincs. ${ }^{17} \mathrm{~A}$ few methods were also developed for its one-carbon higher homologues. ${ }^{18}$ On the other hand, multistep synthetic routes have often been adopted to obtain the HIV-1 protease inhibitors III-V wherein the bicyclic Cp-THF skeleton has been constructed either by intramolecular radical cyclization ${ }^{8,19}$ or intramolecular oxaMichael reaction ${ }^{20}$ of predesigned substrates. We envisaged an effective approach to expeditiously access the CpO-THF moieties and to streamline the synthetic blueprint for the stereoenriched molecular frameworks of the 3-amino-functionalized Cp-THF-derived HIV-1 
protease inhibitors $\mathbf{I V}$ and $\mathbf{V}$ in step-economic, time-saving, and high-yielding process.

In recent years, the renaissance of visible-light-induced photocatalysis has mandated a conspicuous paradigm shift in synthetic organic chemistry by enabling a diverse range of carbon-carbon and carbon-heteroatom bond formations under mild reactions conditions in an energy-efficient manner. ${ }^{21}$ In many such photocatalytic transformations, carboxylic acids have been used as sustainable precursors for the production of carbon-centered radicals that participated in various decarboxylative functionalizations, ${ }^{22}$ among them decarboxylative radical conjugate addition (DcRCA) is emblematic. ${ }^{23}$ Notably, MacMillan and co-workers developed a decarboxylative radical Michael addition of various carboxylic acids to Michael acceptors in the presence of $\left[\operatorname{IrdF}\left(\mathrm{CF}_{3}\right) \mathrm{ppy}_{2}(\mathrm{dtbbpy})\right] \mathrm{PF}_{6}$ under 26 W CFL irradiation (Scheme 1a). ${ }^{23 a}$ Aggarwal and co-workers reported another photocatalytic decarboxylative radical addition of carboxylic acids to vinyl boronic esters in the presence of $\operatorname{Ir}$ (III)based photocatalysts to afford a range of alkyl boronic esters (Scheme 1b). ${ }^{23 \mathrm{~b}}$ Schubert and co-workers performed photocatalytic DcRCA of alkyl and cycloalkyl carboxylic acids to dehydroalanine derivatives in the presence of $4 \mathrm{CzIPN}$ as the photocatalyst under blue light irradiation (Scheme 1c). ${ }^{23 c}$

On the basis of our experience in the field of visible-light-induced atom-transfer radical addition (ATRA) processes, ${ }^{21 a-c, 24}$ we envisioned that the 3-functionalized CpO-THF scaffold could be readily accessible by the photocatalytic decarboxylative radical conjugate addition of carboxylic acids bearing a pendant hydroxyalkyl group that can participate in a sequential oxa-Michael addition to an enone intermediate in an intramolecular fashion (Scheme 1d) paving the way to efficiently and inexpensively access the Cp-3-amino-

Scheme 1. Photocatalytic decarboxylative radical conjugate addition (PC-DcRCA) transformations: Literature precedence versus our synthetic design

\section{(a) MacMillan, 2014: PC-DcRCA to Michael acceptors}

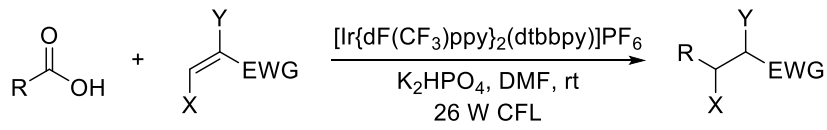

$\mathrm{R}=$ alkyl, cycloalkyl,

$\alpha$-aminoalkyl, $\alpha$-oxyalkyl

$$
\text { (b) Aggarwal, 2018: PC-DcRCA to vinyl boronic esters }
$$

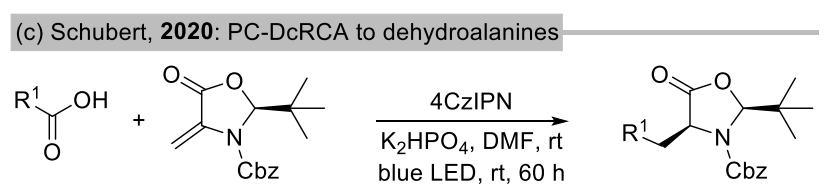

(d) This work: PC-DcRCA-elimination-oxa-Michael reaction

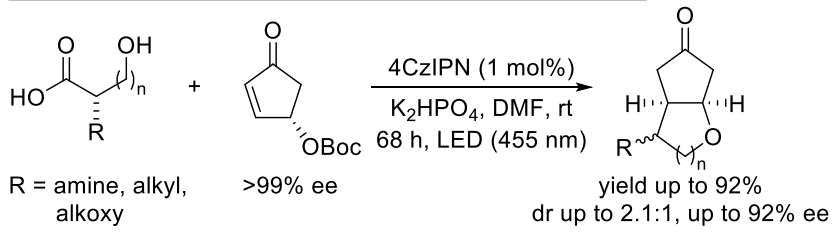

THF-derived HIV-1 protease inhibitors IV and $\mathbf{V}$ upon a few steps of further synthetic manipulations.

\section{RESULTS AND DISCUSSION}

We set out to investigate the plausibility of the proposed concept with the model reaction between renewable, non-edible resourcesderived Boc-protected 4-hydroxy-2-cyclopentenone $1 \mathbf{a}^{25}$ and $\mathrm{N}$ Boc L-serine (2a) in the presence of a range of organic photocatalysts under visible light irradiation with either blue $\left(\lambda_{\max }=455 \mathrm{~nm}\right)$ or green light-emitting diodes $\left(\mathrm{LED} ; \lambda_{\max }=530 \mathrm{~nm}\right)$. Utilizing $1 \mathrm{~mol}$ $\%$ of Fukuzumi's catalyst $\left([\mathrm{Mes} A \mathrm{cr}] \mathrm{ClO}_{4}, \mathrm{E}_{1 / 2}\left(\mathrm{M}^{+} / \mathrm{M}^{*}\right)=2.08 \mathrm{~V}\right.$ vs $\mathrm{SCE}$ ), we observed the formation of the desired product as a diastereomeric mixture of exo- and endo-3a in 14\% yield as determined by NMR analysis of the crude reaction mixture (Table 1, entry 1 ).

Table 1. Optimization studies for sequential photocatalytic

\begin{tabular}{|c|c|c|c|c|}
\hline entry & photocatalyst & base & yield $(\%)^{a}$ & $\begin{array}{l}\mathrm{dr} \mathbf{3 a}(\text { exo- } \\
\text { :endo) }\end{array}$ \\
\hline 1 & {$[\mathrm{MesAcr}] \mathrm{ClO}_{4}$} & $\mathrm{~K}_{2} \mathrm{HPO}_{4}$ & 14 & - \\
\hline 2 & $\mathrm{TPT}$ & $\mathrm{K}_{2} \mathrm{HPO}_{4}$ & 0 & - \\
\hline 3 & Eosin $Y$ & $\mathrm{~K}_{2} \mathrm{HPO}_{4}$ & 0 & - \\
\hline $4^{b}$ & Eosin $Y$ & $\mathrm{~K}_{2} \mathrm{HPO}_{4}$ & 0 & - \\
\hline $5^{b}$ & Rose Bengal & $\mathrm{K}_{2} \mathrm{HPO}_{4}$ & 2 & - \\
\hline 6 & DCA & $\mathrm{K}_{2} \mathrm{HPO}_{4}$ & 8 & - \\
\hline $7^{b}$ & Rhodamine 6G & $\mathrm{K}_{2} \mathrm{HPO}_{4}$ & 59 & $1.8: 1.0$ \\
\hline $8^{b}$ & Rhodamine B & $\mathrm{K}_{2} \mathrm{HPO}_{4}$ & 0 & - \\
\hline 9 & 4CzIPN & $\mathrm{K}_{2} \mathrm{HPO}_{4}$ & 92 & $1.9: 1.0$ \\
\hline $10^{c}$ & 4CzIPN & $\mathrm{K}_{2} \mathrm{HPO}_{4}$ & 82 & $2.0: 1.0$ \\
\hline 11 & none & $\mathrm{K}_{2} \mathrm{HPO}_{4}$ & 0 & - \\
\hline 12 & 4CzIPN & none & 0 & - \\
\hline $13^{d}$ & 4CzIPN & $\mathrm{K}_{2} \mathrm{HPO}_{4}$ & $95(92)^{e}$ & $2.0: 1.0$ \\
\hline $14^{b}$ & $4 \mathrm{CzIPN}$ & $\mathrm{K}_{2} \mathrm{HPO}_{4}$ & 0 & - \\
\hline $15^{f}$ & 4CzIPN & $\mathrm{K}_{2} \mathrm{HPO}_{4}$ & 78 & $1.9: 1.0$ \\
\hline 16 & {$[\mathrm{Ir}]^{\mathrm{g}}$} & $\mathrm{K}_{2} \mathrm{HPO}_{4}$ & 90 & $1.9: 1.0$ \\
\hline
\end{tabular}
DcRCAE-oxa-Michael reaction

${ }^{a}$ NMR yield using 1,1,2,2-tetrachloroethane as an internal standard. ${ }^{b}$ The reaction mixture was irradiated with $530 \mathrm{~nm}$ LED source. 'The reaction was performed under air. ${ }^{d}$ The reaction time was $68 \mathrm{~h}$. ${ }^{e}$ Isolated yield on a $0.75 \mathrm{mmol}$ scale. Irradiated with a $403 \mathrm{~nm}$ LED source. ${ }^{g}[\operatorname{Ir}]=\left[\operatorname{Ir}\left\{\mathrm{dF}\left(\mathrm{CF}_{3}\right] \text { ppy }\right\}_{2}(\mathrm{dtbbpy})\right] \mathrm{PF}_{6}$. 
The use of photocatalysts either with higher excited-state oxidation potential such as 2,4,6-triphenylpyrylium-BF $\mathrm{BF}_{4}\left(\mathrm{TPT}, \mathrm{E}_{1 / 2}\left(\mathrm{M}^{+} / \mathrm{M}^{*}\right)\right.$ $=2.39 \mathrm{Vvs} \mathrm{SCE}$; entry 2 ) or with much lower excited-state oxidation potentials such as Eosin $\mathrm{Y}\left(\mathrm{EY}-\mathrm{Na}_{2}, \mathrm{E}_{1 / 2}\left(\mathrm{M}^{+} / \mathrm{M}^{*}\right)=0.83 \mathrm{~V}\right.$ vs SCE; entries 3 and 4$)$ or Rose Bengal $\left(R B, E_{1 / 2}\left(M^{+} / M^{*}\right)=0.81\right.$ V vs SCE; entry 5) did not appreciably induce the transformation under both blue or green light irradiation and the desired product $\mathbf{3 a}$ either could not be obtained at all or formed only in trace amounts. When 9,10-dicyanoanthracene (DCA, $\mathrm{E}_{1 / 2}\left(\mathrm{M}^{+} / \mathrm{M}^{*}\right)=1.99 \mathrm{~V}$ vs $\mathrm{SCE}$ ) was employed as the photocatalyst, only $8 \%$ NMR yield was observed for 3a (entry 6), but using Rhodamine 6G (Rh6G, $\mathrm{E}_{1 / 2}\left(\mathrm{M}^{+} / \mathrm{M}^{*}\right)=1.18$ $\mathrm{V}$ vs SCE) under green light irradiation resulted in the formation of $3 a$ in $59 \%$ yield (entry 7 ). In contrast, Rhodamine B (RhB, $\mathrm{E}_{1 / 2}\left(\mathrm{M}^{+} / \mathrm{M}^{*}\right)=1.26 \mathrm{~V}$ vs SCE$)$ failed to furnish any desired product under green light irradiation (entry 8). A dramatic enhancement in the efficiency of the transformation was noticed when 1,2,3,5-tetrakis(carbazole-9-yl)-4,6-dicyanobenzene (4CzIPN, E $1 / 2\left(\mathrm{M}^{+} / \mathrm{M}^{*}\right)=$ $1.35 \mathrm{~V}$ vs SCE) was employed under blue light irradiation to form $3 \mathrm{a}$ in $92 \%$ yield (entry 9 ). When the same reaction was performed with 4CzIPN under air, only a slight decrease in efficiency was observed to provide $3 \mathbf{a}$ in $82 \%$ yield (entry 10 ). In all cases, $3 \mathbf{a}$ was formed as an exo/endo mixture of approximately $2: 1$. The photocatalytic nature of the transformation was proved by observing no formation of the product in the absence of a photocatalyst (entry 11 ). The indispensability of a base was recognized upon observing no reaction in its absence (entry 12 ) and $\mathrm{K}_{2} \mathrm{HPO}_{4}$ was found to be the best among the bases that were screened. ${ }^{26}$ Upon increasing the reaction time from $44 \mathrm{~h}$ to $68 \mathrm{~h}$, the yield of the reaction was marginally increased to $95 \%$ (entry 13). When the light-source was changed from blue to green with a $\lambda_{\max }$ of $530 \mathrm{~nm}$, no transformation occurred (entry 14). However, when a near-UV light-source was used $\left(\lambda_{\max }=403 \mathrm{~nm}\right), 3 a$ was obtained in $78 \%$ yield (entry 15 ). Of note, among several iridium based photocatalysts tested, ${ }^{26}\left[\operatorname{IrdF}\left(\mathrm{CF}_{3}\right) \mathrm{ppy}_{2}(\mathrm{dtbbpy})\right] \mathrm{PF}_{6}$ $\left(E_{1 / 2}\left(M^{+} / M^{*}\right)=1.21 \mathrm{~V}\right.$ vs SCE $)$ was also found to be effective to induce the transformation (entry 16). However, in order to develop a greener and more cost-effective synthetic approach, 4CzIPN became the photocatalyst of our choice. Having analyzed the best NMR yield under the conditions described, we synthetically validated the reaction that expeditiously afforded the desired product 3a in $92 \%$ yield on a $0.75 \mathrm{mmol}$ scale (entry 13 and Scheme 2 ). The structure of the major diastereomer exo-3a was confirmed by single crystal X-ray analysis. ${ }^{26}$

Having optimized the reaction conditions, we proceeded to explore the substrate scope and functional group tolerance of the developed synthetic methodology (Scheme 2). When 2-methyl-substituted cyclopentenone derivative $\mathbf{1} \mathbf{b}$ was engaged with $\mathbf{2} \mathbf{a}$, we obtained the corresponding cyclized 3-aminotetrahydrofuran-fused cyclopentanone derivative $3 \mathbf{b}$ in $71 \%$ yield with a $2: 1$ exo/endo ratio with respect to the amino substituent, while the 2-methyl group was oriented exclusively on the exo-face of the bicycle. However, when 5-methyl- or 5-isopropyl substituted cyclopentenone $\mathbf{1 c}$ or $\mathbf{1 d}$ were reacted with $N$-Boc L-serine (2a), we only observed the formation of the corresponding radical-coupled cyclopentenone derivatives $\mathbf{4 b}$ and $\mathbf{4 c}$ in their uncyclized forms, most likely due to a combination of the sterically more hindered and electronically less activated $\alpha, \beta$ enone moiety. To expand the scope of the carboxylic acids as the radical precursors, we investigated several hydroxyalkylated alkyl carboxylic acids instead of amino acids. When 2-(hydroxymethyl)-
Scheme 2. Scope of cyclopentenone derivatives and carboxylic acid radical precursors ${ }^{a}$

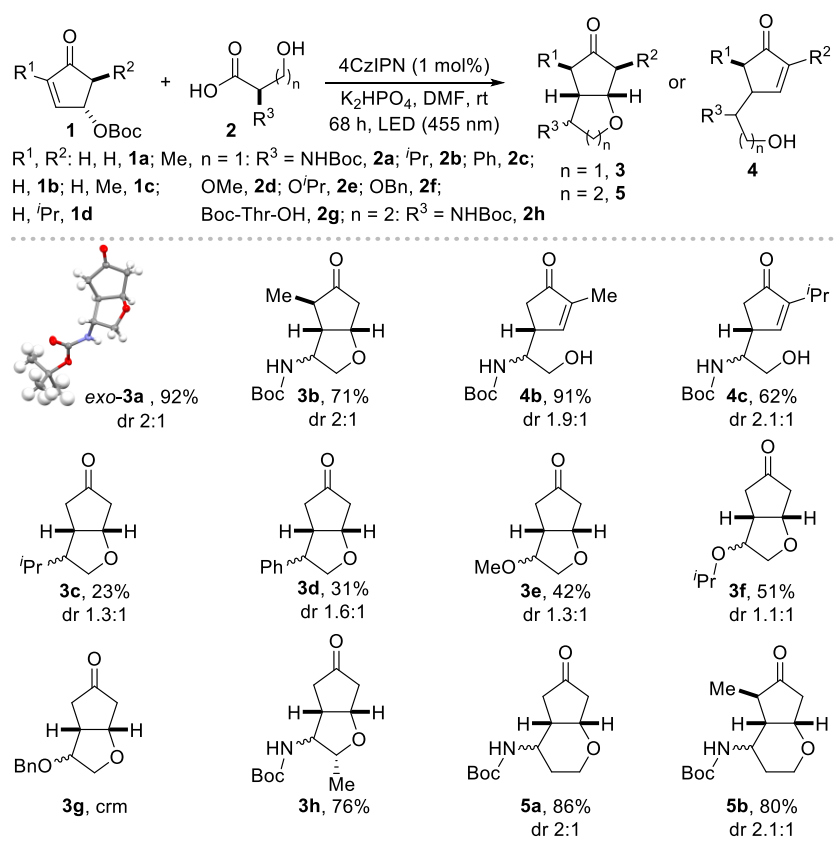

${ }^{a}$ All reactions were carried out with an equimolar mixture of $\mathbf{1}$ and $\mathbf{2}$ on a $0.75 \mathrm{mmol}$ scale in the presence of $1 \mathrm{~mol} \%$ of $4 \mathrm{CzIPN}$ and 1.2 equiv of $\mathrm{K}_{2} \mathrm{HPO}_{4}$ in DMF $(c=0.25 \mathrm{M})$ under $\mathrm{N}_{2}$ after degassing with three cycles of freeze-pump-thaw-backfill and irradiated with a single source of blue LED $(\lambda=455 \mathrm{~nm})$ unless noted otherwise. The diastereomeric ratio was determined from ${ }^{1} \mathrm{H}$ NMR analysis of the crude reaction mixtures.

3-methylbutanoic acid ( $2 \mathbf{b})$ was employed, the desired product $3 c$ was obtained in only $23 \%$. Upon engaging 3-hydroxy-2-phenylpropanoic acid $(\mathbf{2 c})$, the corresponding cyclopentanone derivative 3d formed in a slightly increased yield (31\%) most likely as a result of the formation of a comparatively more stable benzylic radical. The overall low yields in these cases could be explained by the poor stability of the resulting incipient alkyl radicals adjacent to the alkyl groups generated after photocatalytic decarboxylation that impede the process of radical conjugate addition. This reasoning is also in line with the low exo-preference observed (1.3-1.6:1), pointing to an early transition state. In order to increase the nucleophilicity of the incipient radical, we investigated the scope of $a$-alkoxy radical precursors which were synthesized by following literature procedures. ${ }^{26}$ Accordingly, the bicyclic fused alkoxy substituted cyclopentanone derivatives $3 \mathbf{e}$ and $\mathbf{3 f}$ could be obtained in $42 \%$ and $51 \%$ yields, respectively, while aiming at the synthesis of $\mathbf{3 g}$, a benzyloxy substituent was not tolerated. The methodology was also found to be successful when $N$-Boc L-threonine $(\mathbf{2 g})$ was employed as the radical precursor and the corresponding product $3 \mathbf{h}$ was obtained in $76 \%$ yield albeit as a mixture of inseparable diastereomers. Next, we wondered whether the same principle could be exploited to synthesize one-carbon higher homologues of 3-aminotetrahydrofuranfused cyclopentanone derivatives. Commercially available N-Boc Lhomoserine $(\mathbf{2} \mathbf{h})$ was employed as the radical precursor and reacted with 1a, and indeed we were pleased to observe the formation of the corresponding 4-aminotetrahydropyran-fused cyclopentanone derivative $\mathbf{5 a}$ in $86 \%$ yield. Likewise, $\mathbf{1} \mathbf{b}$ as the substrate gave rise to 5 - 
methyl-substituted bicyclic tetrahydropyran-fused cyclopentanone $\mathbf{5 b}$ in $80 \%$ yield.

We next pursued the construction of structurally more intricate molecular frameworks, employing commercially available 4-hydroxy proline derivative $\mathbf{6}$ in the reaction with $\mathbf{1 a}$ and $\mathbf{1 b}$. Gratifyingly, also in these cases an efficient photocatalytic reaction took place to yield a mixture of cyclized (7) and uncyclized (4) products, which upon treatment with $\mathrm{KF}$ and $\mathrm{Al}_{2} \mathrm{O}_{3}$ were smoothly converted to $\mathbf{7 a}$ and $\mathbf{7 b}$, respectively in $87 \%$ and $70 \%$ overall yield (Scheme 3). ${ }^{27}$ Remarkably, full stereocontrol at C-5 in 7 is observed for both enantiomers of $\mathbf{1 a}$ (the observed d.r. in 7 (relative stereochemistry at C-5a, C-6, C-8a) is a consequence of the racemic mixture of $1 \mathrm{a}$ that was employed), apparently being directed by the stereocenter at C-4 in hydroxyproline 6.

Scheme 3. Syntheses of cyclopentanone-fused 2,5-methanooxazepines

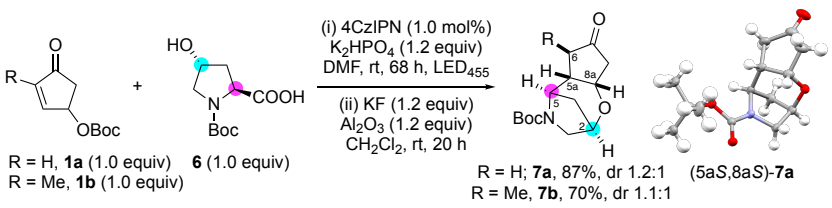

Moving towards HIV-1 protease inhibitors IV and $\mathbf{V}$ in their enantioenriched forms, we investigated the developed sequence with enantiopure substrate $(S)$-1a in a stereoselective fashion. Previously, we reported the reaction between 4-O-Boc-cyclopent-2-enone $(R)$ 1a and Grignard reagents in the presence of copper (Scheme 4a), which proceeded with high stereoselectivity initiated by the nucleophilic, conjugate addition anti to the OBoc group to diastereo- and enantiomerically pure cyclopentenones of type $8{ }^{28}$ When we reacted enantiopure $(S)$-1a with diphenylacetic acid (9) as a stable radical precursor under the present conditions, we observed the formation of the corresponding 4-benzhydryl-substituted 2-cyclopentenone derivative $(S)-\mathbf{1 0}$ in $76 \%$ yield with remarkable enantiomeric excess ( $96 \%$ ee, Scheme $4 \mathrm{~b}$ ) given that in contrast to the ionic process to $\mathbf{8}$ the radical addition to $(S)$-10 was assumed to proceed via an earlier, thus less selective transition state.

Scheme 4. Stereoselective conjugate addition: Nucleophilic vs radical process

(a) Stereoselective nucleophilic conjugate addition: Reiser, 2015

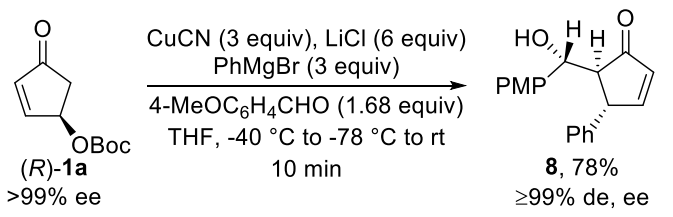

(b) Stereoselective radical conjugate addition: Present work

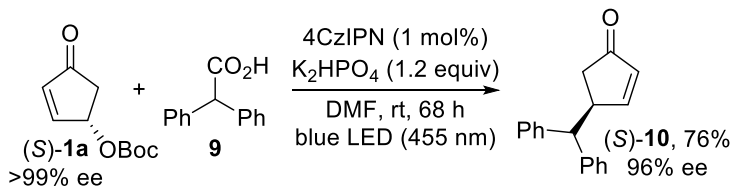

To synthesize the requisite synthetic precursors for $\mathbf{I V}$ and $\mathbf{V}$ in large quantity in racemic forms, we proceeded to perform the benchmark reaction between $\mathbf{1 a}$ and $\mathbf{2 a}$ on a multigram-scale. Accordingly,

when an equimolar mixture of $\mathbf{1 a}$ and $\mathbf{2 a}$ were reacted in $45 \mathrm{mmol}$ scale in the presence of $2.5 \mathrm{~mol} \% 4 \mathrm{CzIPN}$ in a specially designed large-scale photocatalytic reaction set-up with blue LED strips as the irradiation source, ${ }^{26}$ we observed the formation of $3 \mathbf{a}$ (exo/endo 2:1) along with some of the corresponding uncyclized cyclopentenone derivative (approx. 20\%) as an inseparable mixture. Gratifyingly, by treating the mixture with $\mathrm{KF}$ and $\mathrm{Al}_{2} \mathrm{O}_{3}$ in dichloromethane at room temperature, the desired cyclization could be completed to obtain 3a in $81 \%$ yield (Scheme 5). ${ }^{27}$

Scheme 5. Multigram-scale experiment for the sequential photocatalytic decarboxylative radical addition-elimination-oxaMichael reaction

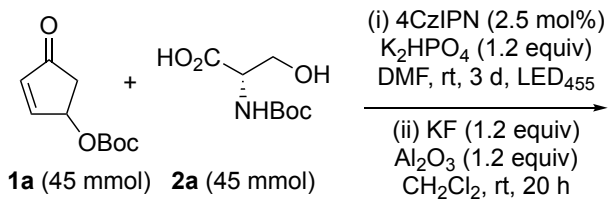

From the successful scaling-up of the photocatalytic DcRCAEoxa-Michael reaction strategy with racemic substrate (1a) we were set to synthesize IV and $\mathbf{V}$ in diastereo- and enantiomerically enriched forms (Scheme 6). Radical coupling between (S)-1a and 2a was carried out on a $5 \mathrm{mmol}$ scale in the presence of $1 \mathrm{~mol} \% 4 \mathrm{CzIPN}$ in a large-sized pressure tube $e^{26}$ to obtain $3 a$ in $86 \%$ yield as a difficult to separate diastereomeric mixture of exo-(3R)-3a and endo-(3S)-3a in a 2.2:1 ratio. The carbonyl moieties of exo-(3R)-3a and endo$(3 S)$-3a were stereoselectively reduced by the treatment of the diastereomeric mixture with sodium borohydride in a 1:1 mixture of $\mathrm{MeOH}$ and THF at $0{ }^{\circ} \mathrm{C}-\mathrm{rt}$ for $2 \mathrm{~h}$ and the corresponding diastereomers of the alcohol derivatives (3R)-11 and (3S)-11 were obtained in $81 \%$ combined yield. Gratifyingly, the two diastereomers could be readily separated at this stage by column chromatographic purification and the subsequent steps were carried out with the individual dastereopure compounds. The relative stereochemistry in (3R)-11 was confirmed by single crystal $\mathrm{X}$-ray analysis, which allowed us to unambiguously assign the stereochemistry of all products along the routes. (3R)-11 and (3S)-11 were converted to their corresponding $N$-methyl carbamate derivatives (3R)-12 and (3S)-12, respectively, by deprotection of the $N$-Boc groups under acidic conditions and reprotection of the free amine groups with methyl chloroformate in $83 \%$ overall yield each over two steps. Next, each of the two diastereomers were treated with 4-nitrophenyl chloroformate in the presence of pyridine ${ }^{8 a}$ and the corresponding activated carbonates (3R)13 and (3S)-13 were obtained in $85 \%$ yield in both cases. The enantiomeric excesses of these diastereomers were determined at this stage and found to be $84 \%$ and $92 \%$ ee, respectively, suggesting that the initial coupling between $(S)$-1a and $\mathbf{2 a}$ took place with somewhat lower anti-selectivity compared to the formation of

$(S)$-10 ( $c f$. Scheme 4). The other required part $\mathbf{1 7}$ of the targeted inhibitors, the P1-ligand, was synthesized by following methods as established by Ghosh and co-workers. ${ }^{29}$ The endgame of the total synthesis was carried out with the coupling of 17 with (3R)-13 and (3S)-13 to furnish the HIV-1 protease inhibitors (3S)-IV and (3R)$\mathbf{V}$ in $89 \%$ and $87 \%$ yields, respectively ( $\mathrm{dr} \geq 20: 1,91 \%$ and $86 \%$ ee, respectively). ${ }^{8 a}$ 

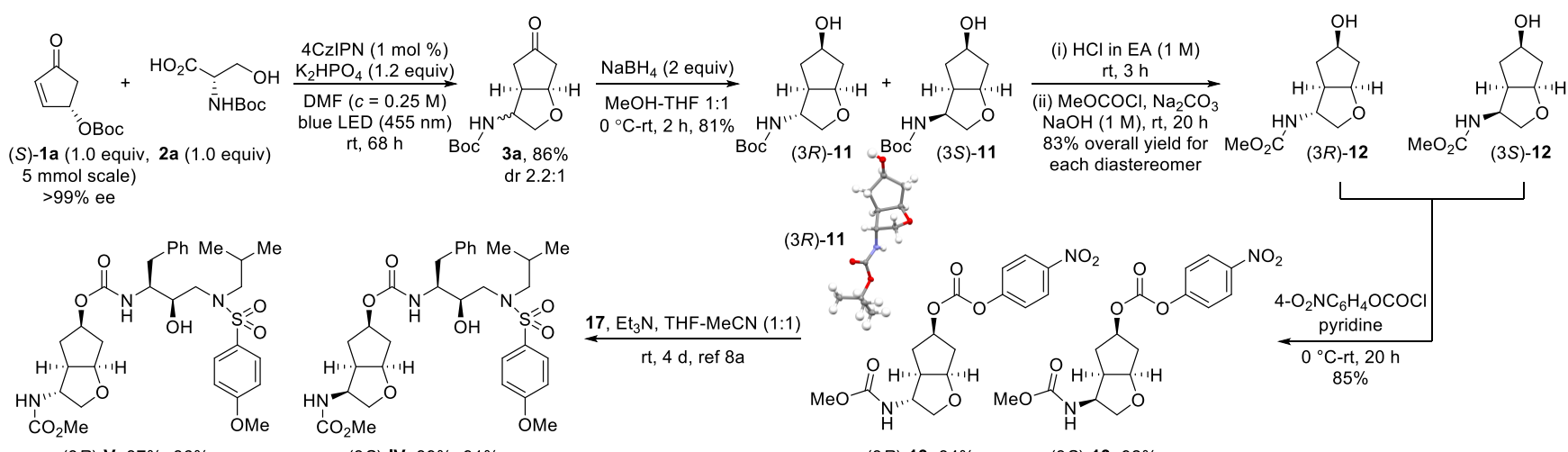

$(3 R)-\mathbf{V}, 87 \%, 86 \%$ ee

(3S)-IV, $89 \%, 91 \%$ ee

$(3 R)-13,84 \%$ ee $\quad(3 S)-13,92 \%$ ee

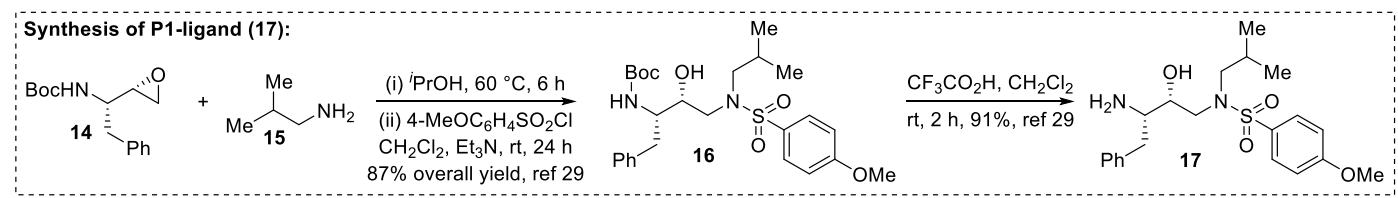

\section{MECHANISM}

On the basis of our experimental observations, a plausible mechanism is postulated (Scheme 7). Presumably, the reaction initiates with the deprotonation of carboxylic acid $\mathbf{2}$ by the base present in the reaction medium. Upon irradiation with a blue LED $\left(\lambda_{\max }=455\right.$ $\mathrm{nm})$, the excited photocatalyst oxidizes the newly formed carboxylate anion (A) via a single-electron transfer (SET) process and subsequent extrusion of $\mathrm{CO}_{2}$ generates the alkyl radical $\mathbf{B}$ which adds to cyclopentenone $\mathbf{1}$ furnishing the open-shell intermediate $\mathbf{C}$. The incipient carbon-centered radical is then reduced to its corresponding carbanionic species $\mathbf{D}$ by the reduced photocatalyst $\left(\mathrm{PC}^{*-}\right)$, thereby closing the photocatalytic cycle. Subsequent formation of the tautomer $\mathbf{E}$ and expulsion of the OBoc group generates the uncyclized cyclopentenone derivative $\mathbf{4}$ which may undergo an intramolecular

Scheme 7. A probable mechanism of the sequential photocatalytic decarboxylative radical conjugate addition-eliminationoxa-Michael reaction

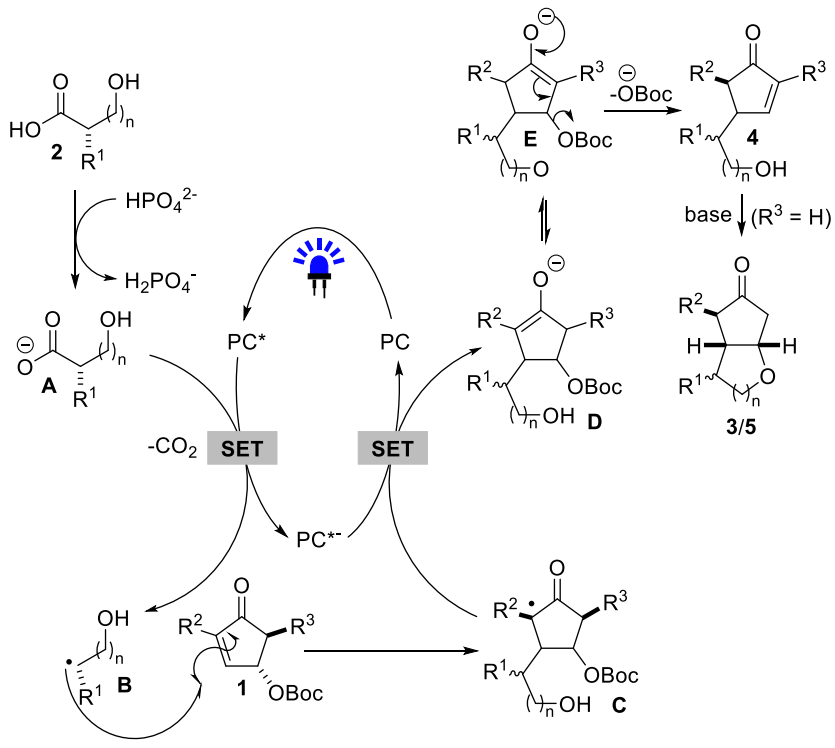

oxa-Michael reaction by the pendant hydroxyl group under basic conditions and ultimately furnishes the cyclopentanonyl-fused cyclic ether frameworks $\mathbf{3}$ or $\mathbf{5}$.

\section{CONCLUSIONS}

To conclude, we have developed a novel visible-light-mediated synthetic route to access structurally variegated cyclopentanonylfused functionalized cyclic ether derivatives in the presence of an inexpensive organic photocatalyst. In particular, we have been able to move the previously developed cascade of nucleophilic conjugate addition, isomerization, elimination of 4-OBoc-cyclopentenones to the radical regime and moreover, extend the sequence by and additional conjugate addition to the newly formed cyclopentenone moiety. By applying this strategy, we have achieved the total syntheses of the two diastereomers of a potent HIV-1 protease inhibitor in enantioenriched forms from easily obtainable renewable resources-derived starting materials.

\section{ASSOCIATED CONTENT}

Supporting Information. The Supporting Information is available free of charge at https://pubs.acs.org.

Crystal structures of 3R-11 (CCDC 2085696), exo-3a (CCDC 2085697), 7a (CCDC 2085792).

Experimental procedures and spectral data (PDF)

\section{AUTHOR INFORMATION}

\section{Corresponding Author}

Oliver Reiser - Institut für Organische Chemie, Universität Regensburg, Universitätsstraße 31, 93053 Regensburg, Germany; orcid.org/0000-0003-1430-573X; Email: oliver.reiser@chemie.uni-regensburg.de

\section{Authors}

Tomislav Krolo - Institut für Organische Chemie, Universität Regensburg, Universitätsstraße 31, 93053 Regensburg, Germany; orcid.org/0000-0003-1736-2844; Email: Tomislav.Krolo@chemie.uniregensburg.de 
Aditya Bhattacharyya - Institut für Organische Chemie, Universität Regensburg, Universitätsstraße 31, 93053 Regensburg, Germany; orcid.org/0000-0001-7011-2102; Email: Aditya.Bhattacharyya@chemie.uni-regensburg.de

\section{Funding Sources}

The authors thank DFG (RE948/18-1) for financial support. A.B. thanks the European Union's Framework Programme for Research and Innovation Horizon 2020 (2014-2020) for the fellowship received under the Marie Skłodowska-Curie Grant Agreement No. 795161.

\section{Notes}

The authors declare no competing financial interest.

\section{ACKNOWLEDGMENTS}

We thank Mr. Josef Kiermaier and Mr. Wolfgang Söllner for Mass analysis as well as Dr. Michael Bodensteiner, Ms. Sabine Stempfhuber and Ms. Birgit Hischa for X-Ray analysis.

\section{ABBREVIATIONS}

HIV, human immunodeficiency viruses; AIDS, acquired immune deficiency syndrome; IC $\mathrm{I}_{50}$, half maximal inhibitory concentration; LED, light-emitting diode; FDA, U.S. Food and Drug Administration; $\mathrm{Cp}$, cyclopentane; $\mathrm{CpO}$, cyclopentanone; SET, single-electron transfer.

\section{REFERENCES}

(1) Gu, B.-B.; Wu, W.; Jiao, F.-R.; Jiao, W.-h.; Li, L.; Sun, F.; Wang, S.-P.; Yang, F.; Lin, H.-W., Asperflotone, an 8(14 $\rightarrow 15)$-abeo-Ergostane from the Sponge-Derived Fungus Aspergillus flocculosus 16D-1. J. Org. Chem. 2019, $84,300-306$

(2) Nihei, K.-i.; Hanke, F. J.; Asaka, Y.; Matsumoto, T.; Kubo, I., Insect Antifeedants from Tropical Plants. II: Structure of Zumsin. J. Agric. Food Chem. 2002, 50, 5048-5052.

(3) (a) Ghosh, A. K.; Xi, K., Enantioselective Synthesis of (-)Platensimycin Oxatetracyclic Core by Using an Intramolecular Diels-Alder Reaction. Org. Lett. 2007, 9, 4013-4016. (b) Ghosh, A. K.; Xi, K., Total Synthesis of (-)-Platensimycin, a Novel Antibacterial Agent. J. Org. Chem. 2009, 74, 1163-1170.

(4) (a) Murai, K.; Katoh, S.-i.; Urabe, D.; Inoue, M., A radical-based approach for the construction of the tetracyclic structure of resiniferatoxin. Chem. Sci. 2013, 4, 2364-2368. (b) Hashimoto, S.; Katoh, S.-i.; Kato, T.; Urabe, D.; Inoue, M., Total Synthesis of Resiniferatoxin Enabled by RadicalMediated Three-Component Coupling and 7-endo Cyclization. J. Am. Chem. Soc. 2017, 139, 16420-16429.

(5) (a) Hirose, S.; Kamatari, Y. O.; Yanase, E., Mechanism of oolongtheanin formation via three intermediates. Tetrahedron Lett. 2020, 61, 151601-151605. (b) Hirose, S.; Tomatsu, K.; Yanase, E., Isolation of key intermediates during formation of oolongtheanins. Tetrahedron Lett. 2013, 54, 7040-7043.

(6) Jing, C.; Mallah, S.; Kriemen, E.; Bennett, S. H.; Fasano, V.; Lennox, A. J. J.; Hers, I.; Aggarwal, V. K., Synthesis, Stability, and Biological Studies of Fluorinated Analogues of Thromboxane A 2 . ACS Cent. Sci. 2020, 6, 9951000.

(7) Wakita, H.; Yoshiwara, H.; Nishiyama, H.; Nagase, H., Total synthesis of optically active $m$-phenylene $\mathrm{PGI}_{2}$ derivative: Beraprost. Heterocycles 2000, 53, 1085-1110.

(8) (a) Ghosh, A. K.; Chapsal, B. D.; Steffey, M.; Agniswamy, J.; Wang, Y.-F.; Amano, M.; Weber, I. T.; Mitsuya, H., Substituent effects on P2cyclopentyltetrahydrofuranyl urethanes: Design, synthesis, and X-ray studies of potent HIV-1 protease inhibitors. Bioorg. Med. Chem. Lett. 2012, 22, 2308-2311. (b) Ghosh, A. K.; Chapsal, B. D.; Parham, G. L.; Steffey, M.; Agniswamy, J.; Wang, Y.-F.; Amano, M.; Weber, I. T.; Mitsuya, H., Design of HIV-1 Protease Inhibitors with C3-Substituted Hexahydrocyclopentafuranyl Urethanes as P2-Ligands: Synthesis, Biological Evaluation, and Protein-Ligand X-ray Crystal Structure. J.Med. Chem. 2011, 54, 5890-5901. (c) Ghosh, A. K.; Sridhar, P. R.; Leshchenko, S.; Hussain, A. K.; Li, J.; Kovalevsky, A. Y.; Walters, D. E.; Wedekind, J. E.; Grum-Tokars, V.; Das, D.; Koh, Y.; Maeda, K.; Gatanaga, H.; Weber, I. T.; Mitsuya, H., Structure-Based Design of Novel HIV-1 Protease Inhibitors To Combat Drug Resistance. J. Med. Chem. 2006, 49, 5252-5261.

(9) Cottiglia, F.; Casu, L.; Leonti, M.; Caboni, P.; Floris, C.; Busonera, B.; Farci, P.; Ouhtit, A.; Sanna, G., Cytotoxic Phloroglucinols from the Leaves of Myrtus communis. J. Nat. Prod. 2012, 75, 225-229.

(10) Miyano, M.; Dorn, C. R., Prostaglandins. V. Synthesis of $d l-$ Dihydroprostaglandin $\mathrm{E}_{1}$ and $\Delta^{8(12)}$-Dehydroprostaglandin $\mathrm{E}_{1}$. J. Org. Chem. 1972, 37, 1818-1823.

(11) Weng, J.-R.; Chung, M.-I.; Yen, M.-H.; Lin, C.-N.; Wu, R.-R., Hypertricone, a Constituent with a Novel Skeleton, Isolated from Hypericum geminiflorum. Helv. Chim. Acta 2001, 84, 1976-1979.

(12) Coulthard, G.; Erb, W.; Aggarwal, V. K., Stereocontrolled organocatalytic synthesis of prostaglandin $\mathrm{PGF}_{2 \alpha}$ in seven steps. Nature 2012, 489, 278-281.

(13) Lv, Z.; Chen, B.; Zhang, C.; Liang, G., Total Syntheses of Trichorabdal A and Maoecrystal Z. Chem. - Eur. J. 2018, 24, 9773-9777.

(14) (a) Paquette, L. A.; Zhao, Z.; Gallou, F.; Liu, J., New Photorearrangements of 2-Cyclopentenones. The Genesis and Fate of Cyclopropylcarbinyl Biradical Intermediates. J. Am. Chem. Soc. 2000, 122, 1540-1541. (b) Sampath, V.; Lund, E. C.; Knudsen, M. J.; Olmstead, M. M.; Schore, N. E., Cobalt-based route to highly functionalized hydrazulenes. J. Org. Chem. 1987, 52, 3595-3603. (c) Mehta, G.; Srikrishna, A.; Reddy, A. V.; Nair, M. S., A novel, versatile synthetic approach to linearly fused tricyclopentanoids via photothermal olefin metathesis. Tetrahedron 1981, $37,4543-4559$.

(15) Baranovsky, A. V.; Bolibrukh, D. A.; Bull, J. R., Synthesis of 3Methoxy-16 $\alpha$-nitro-14,17-ethenoestra-1,3,5(10)-trien-17 $\beta$-yl Acetate and Fragmentation-Mediated Pathways to $14 \beta, 15 \beta$-Fused $N$-Heterocycles and 14 $\beta$-Functionalised Alkyl Derivatives. Eur. J. Org. Chem. 2007, 445-454.

(16) Inoue, M.; Yamashita, S.; Ishihara, Y.; Hirama, M., Two Convergent Routes to the Left-Wing Fragment of Ciguatoxin CTX3C Using O,S-Acetals As Key Intermediates. Org. Lett. 2006, 8, 5805-5808.

(17) Montgomery, J.; Chevliakov, M. V.; Brielmann, H. L., NickelCatalyzed Heterocycle Construction with Stereoselective Exocyclic Alkene Introduction. Tetrahedron 1997, 53, 16449-16462.

(18) (a) Finch, H.; Mjalli, A. M. M.; Montana, J. G.; Roberts, S. M.; Taylor, R. J. K., Sulfone-mediated cyclobutanone to $\alpha$ alkoxycyclopentanone ring expansion reactions; scope, limitations and applications. Tetrahedron 1990, 46, 4925-4950. (b) Herndon, J. W.; Matasi, J. J., Hydrogenation of Vinylogous Esters. Tetrahedron Lett. 1992, 33, 57255728. (c) Yan, J.; Herndon, J. W., Stereoselective Preparation of Vitamin D Precursors Using the Intramolecular Coupling of Alkynes and Cyclopropylcarbene-Chromium Complexes: A Formal Total Synthesis of ( \pm )-Vitamin $\mathrm{D}_{3}$. J. Org. Chem. 1998, 63, 2325-2331. (d) Marmsater, F. P.; Vanecko, J. A.; West, F. G., Cyclic oxonium ylides: building blocks for iterative synthesis of polycyclic ethers. Tetrahedron 2002, 58, 2027-2040.

(19) (a) Ghosh, A. K.; Takayama, J., Enantioselective Synthesis of Cyclopentyltetrahydrofuran (Cp-THF), an Important High-Affinity P2Ligand for HIV-1 Protease Inhibitors. Tetrahedron Lett. 2008, 49, 34093412. (b) Ghosh, A. K.; Chapsal, B. D.; Baldridge, A.; Ide, K.; Koh, Y.; Mitsuya, H., Design and Synthesis of Stereochemically Defined Novel Spirocyclic P2-Ligands for HIV-1 Protease Inhibitors. Org. Lett. 2008, 10, 5135-5138.

(20) Mihara, H.; Sohtome, Y.; Matsunaga, S.; Shibasaki, M., ChiralCatalyst-Based Convergent Synthesis of HIV Protease Inhibitor GRL06579A. Chem. Asian J. 2008, 3, 359-366.

(21) (a) Hossain, A.; Bhattacharyya, A.; Reiser, O., Copper's rapid ascent in visible-light photoredox catalysis. Science 2019, 364, eaav9713. (b) Reiser, O., Shining Light on Copper: Unique Opportunities for Visible-LightCatalyzed Atom Transfer Radical Addition Reactions and Related Processes. Acc. Chem. Res. 2016, 49, 1990-1996. (c) Abderrazak, Y.; Bhattacharyya, A.; Reiser, O., Visible-Light-Induced Homolysis of EarthAbundant Metal-Substrate Complexes: A Complementary Activation 
Strategy in Photoredox Catalysis. Angew. Chem. Int. Ed. 2021, DOI: 10.1002/anie.202100270. (d) Prier, C. K.; Rankic, D. A.; MacMillan, D. W. C., Visible Light Photoredox Catalysis with Transition Metal Complexes: Applications in Organic Synthesis. Chem. Rev. 2013, 113, 5322-5363. (e) Marzo, L.; Pagire, S. K.; Reiser, O.; Koenig, B., Visible-Light Photocatalysis: Does It Make a Difference in Organic Synthesis? Angew. Chem., Int. Ed. 2018, 57, 10034-10072. (f) Romero, N. A.; Nicewicz, D. A., Organic Photoredox Catalysis. Chem. Rev. 2016, 116, 10075-10166. (g) Ravelli, D.; Protti, S.; Fagnoni, M., Carbon-Carbon Bond Forming Reactions via Photogenerated Intermediates. Chem. Rev. 2016, 116, 9850-9913. (h) Twilton, J.; Le, C.; Zhang, P.; Shaw, M. H.; Evans, R. W.; MacMillan, D. W. C., The merger of transition metal and photocatalysis. Nat. Rev. Chem. 2017, 1,0052 .

(22) (a) Xuan, J.; Zhang, Z.-G.; Xiao, W.-J., Visible-Light-Induced Decarboxylative Functionalization of Carboxylic Acids and Their Derivatives. Angew. Chem. Int. Ed. 2015, 54, 15632-15641. (b) Cartwright, K. C.; Tunge, J. A., Organophotoredox/palladium dual catalytic decarboxylative $\mathrm{Csp}^{3}-\mathrm{Csp}^{3}$ coupling of carboxylic acids and $\pi$-electrophiles. Chem. Sci. 2020, 11, 8167-8175.

(23) (a) Chu, L.; Ohta, C.; Zuo, Z.; MacMillan, D. W. C., Carboxylic Acids as A Traceless Activation Group for Conjugate Additions: A ThreeStep Synthesis of ( \pm )-Pregabalin. J. Am. Chem. Soc. 2014, 136, 10886-10889. (b) Noble, A.; Mega, R. S.; Pflästerer, D.; Myers, E. L.; Aggarwal, V. K., Visible-Light-Mediated Decarboxylative Radical Additions to Vinyl Boronic Esters: Rapid Access to $\gamma$-Amino Boronic Esters. Angew. Chem. Int.Ed. 2018 , 57, 2155-2159. (c) Zhang, O.; Schubert, J. W., Derivatization of Amino Acids and Peptides via Photoredox-Mediated Conjugate Addition. J. Org. Chem. 2020, 85, 6225-6232. (d) Zhang, S.; Tan, Z.; Zhang, H.; Liu, J.; Xu, W.; Xu, K., An Ir-photoredox-catalyzed decarboxylative Michael addition of glyoxylic acid acetal as a formyl equivalent. Chem. Commun. 2017, 53, 11642-11645. (e) Miyake, Y.; Nakajima, K.; Nishibayashi, Y., Visible lightmediated oxidative decarboxylation of arylacetic acids into benzyl radicals: addition to electron-deficient alkenes by using photoredox catalysts. Chem. Commun. 2013, 49, 7854. (f) Gualandi, A.; Matteucci, E.; Monti, F.; Baschieri, A.; Armaroli, N.; Sambri, L.; Cozzi, P. G., Photoredox radical conjugate addition of dithiane-2-carboxylate promoted by an iridium(III) phenyl-tetrazole complex: a formal radical methylation of Michael acceptors. Chem. Sci. 2017, 8, 1613-1620. (g) Wang, G.-Z.; Shang, R.; Cheng, W.-M.; Fu, Y., Decarboxylative 1,4-Addition of a-Oxocarboxylic Acids with Michael Acceptors Enabled by Photoredox Catalysis. Org. Lett. 2015, 17, 4830-4833. (h) Chen, G.; Li, C.; Peng, J.; Yuan, Z.; Liu, P.; Liu, X., Silver-promoted decarboxylative radical addition/annulation of oxamic acids with gem-difluoroolefins: concise access to $\mathrm{CF}_{2}$-containing 3,4dihydroquinolin-2-ones. Org. Biomol. Chem. 2019, 17, 8527-8532. (i)
Ernouf, G.; Chirkin, E.; Rhyman, L.; Ramasami, P.; Cintrat, J. C., Photochemical Strain-Release-Driven Cyclobutylation of C $\left(\mathrm{sp}^{3}\right)$-Centered Radicals. Angew. Chem. Int. Ed. 2020, 59, 2618-2622. (j) FernandezRodriguez, P.; Legros, F.; Maier, T.; Weber, A.; Méndez, M.; Derdau, V.; Hessler, G.; Kurz, M.; Villar-Garea, A.; Ruf, S., Photoinduced Decarboxylative Radical Addition Reactions for Late Stage Functionalization of Peptide Substrates. Eur. J. Org. Chem. 2021, 2021, 782787. (k) Dang, H. T.; Haug, G. C.; Nguyen, V. T.; Vuong, N. T. H.; Nguyen, V. D.; Arman, H. D.; Larionov, O. V., Acridine Photocatalysis: Insights into the Mechanism and Development of a Dual-Catalytic Direct Decarboxylative Conjugate Addition. ACS Catal. 2020, 10, 11448-11457. (1) Gingipalli, L.; Boerth, J.; Emmons, D.; Grebe, T.; Hatoum-Mokdad, H.; Peng, B.; Sha, L.; Tentarelli, S.; Wang, H.; Wu, Y.; Zheng, X.; Edmondson, S.; Gopalsamy, A., Photoredox Catalysis: 1,4-Conjugate Addition of $N$ Methyl Radicals to Electron-Deficient Olefins via Decarboxylation of $\mathrm{N}$ Substituted Acetic Acids. Org. Lett. 2020, 22, 3418-3422.

(24) (a) Engl, S.; Reiser, O., Copper makes the difference: Visible-LightMediated Atom Transfer Radical Addition (ATRA) Reactions of Iodoform with Olefins. ACS Catal. 2020, 10, 9899-9906. (b) Engl, S.; Reiser, O., Making Copper Photocatalysis Even More Robust and Economic: Photoredox Catalysis with $\left[\mathrm{Cu}^{\mathrm{II}}(\mathrm{dmp})_{2} \mathrm{Cl}\right] \mathrm{Cl}$. Eur. J. Org. Chem. 2020, 2020, 1523-1533. (c) Hossain, A.; Engl, S.; Lutsker, E.; Reiser, O., Visiblelight-mediated regioselective chlorosulfonylation of alkenes and alkynes: introducing the $\mathrm{Cu}$ (II) complex $\left[\mathrm{Cu}(\mathrm{dap}) \mathrm{Cl}_{2}\right]$ to photochemical ATRA reactions. ACS Catal. 2019, 9, 1103-1109. (d) Foell, T.; Rehbein, J.; Reiser O., $\operatorname{Ir}(\text { ppy })_{3}$-Catalyzed, Visible-Light-Mediated Reaction of $\alpha$-Chloro Cinnamates with Enol Acetates: An Apparent Halogen Paradox. Org. Lett. 2018, 20, 5794-5798.

(25) Ulbrich, K.; Kreitmeier, P.; Reiser, O., Microwave- or microreactorassisted conversion of furfuryl alcohols into 4-hydroxy-2-cyclopentenones. Synlett 2010, 2037-2040.

(26) See the Supporting Information for details.

(27) Kilic, H.; Bayindir, S.; Erdogan, E.; Saracoglu, N., Synthesis of highly $\mathrm{N}$-substituted indole library via conjugate additions of indoline and their synthetic tool potentials. Tetrahedron 2012, 68, 5619-5630.

(28) Arisetti, N.; Reiser, O., Traceless Stereoinduction for the Enantiopure Synthesis of Substituted-2-Cyclopentenones. Org. Lett. 2015, 17, 94-97.

(29) Ghosh, A. K.; Fidanze, S., Transition-State Mimetics for HIV Protease Inhibitors: Stereocontrolled Synthesis of Hydroxyethylene and Hydroxyethylamine Isosteres by Ester-Derived Titanium Enolate Syn and Anti-Aldol Reactions. J. Org. Chem. 1998, 63, 6146-6152. 


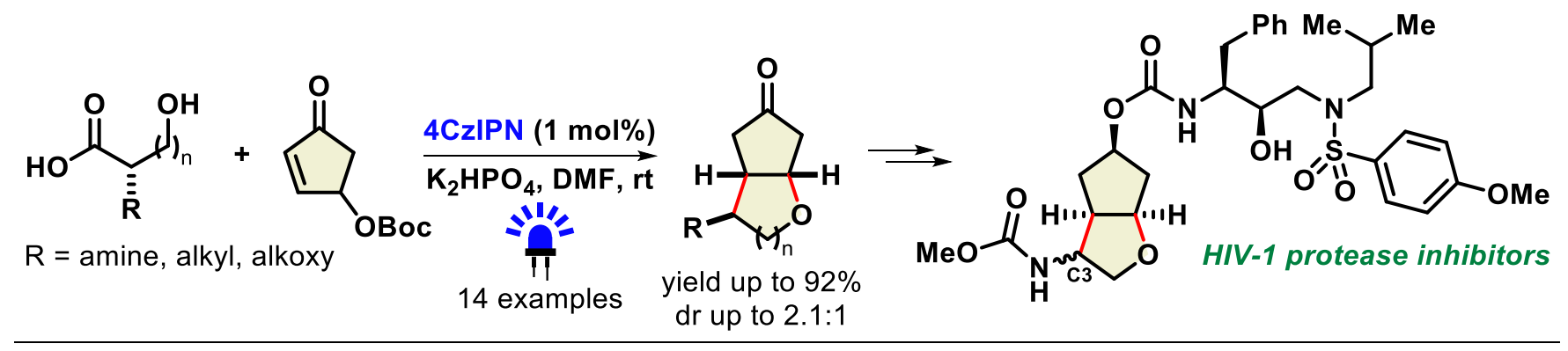

